\title{
Energy Efficient Hybrid Dual Axis Solar Tracking System
}

\author{
Rashid Ahammed Ferdaus, ${ }^{1}$ Mahir Asif Mohammed, ${ }^{1}$ Sanzidur Rahman, ${ }^{1}$ \\ Sayedus Salehin, ${ }^{2}$ and Mohammad Abdul Mannan ${ }^{1}$ \\ ${ }^{1}$ Faculty of Engineering, American International University-Bangladesh, Road 14, Kemal Ataturk Avenue, Banani, \\ Dhaka 1213, Bangladesh \\ ${ }^{2}$ Department of Mechanical and Chemical Engineering, Islamic University of Technology (IUT), \\ Organisation of Islamic Cooperation (OIC), Board Bazar, Gazipur 1704, Bangladesh
}

Correspondence should be addressed to Rashid Ahammed Ferdaus; rashidferdaus@yahoo.com

Received 16 April 2014; Accepted 16 June 2014; Published 8 July 2014

Academic Editor: Jayanta Deb Mondol

Copyright (C) 2014 Rashid Ahammed Ferdaus et al. This is an open access article distributed under the Creative Commons Attribution License, which permits unrestricted use, distribution, and reproduction in any medium, provided the original work is properly cited.

\begin{abstract}
This paper describes the design and implementation of an energy efficient solar tracking system from a normal mechanical single axis to a hybrid dual axis. For optimizing the solar tracking mechanism electromechanical systems were evolved through implementation of different evolutional algorithms and methodologies. To present the tracker, a hybrid dual-axis solar tracking system is designed, built, and tested based on both the solar map and light sensor based continuous tracking mechanism. These light sensors also compare the darkness and cloudy and sunny conditions assisting daily tracking. The designed tracker can track sun's apparent position at different months and seasons; thereby the electrical controlling device requires a real time clock device for guiding the tracking system in seeking solar position for the seasonal motion. So the combination of both of these tracking mechanisms made the designed tracker a hybrid one. The power gain and system power consumption are compared with a static and continuous dual axis solar tracking system. It is found that power gain of hybrid dual axis solar tracking system is almost equal to continuous dual axis solar tracking system, whereas the power saved in system operation by the hybrid tracker is $44.44 \%$ compared to the continuous tracking system.
\end{abstract}

\section{Introduction}

During the last few years the renewable energy sources like solar energy have gained much importance in all over the world. Different types of renewable or green energy resources like hydropower, wind power, and biomass energy are currently being utilized for the supply of energy demand. Among the conventional renewable energy sources, solar energy is the most essential and prerequisite resource of sustainable energy $[1,2]$.

Solar energy refers to the conversion of the sun's rays into useful forms of energy, such as electricity or heat. A photovoltaic cell, commonly called a solar cell or PV, is the technology used to convert solar energy directly into electrical power. The physics of the PV cell (solar cell) is very similar to the classical p-n junction diode. Sunlight is composed of photons or particles of solar energy. Semiconductor materials within the PV cell absorb sunlight which knocks electrons from their atoms, allowing electrons to flow through the material to produce electricity $[3,4]$. Because of its cleanliness, ubiquity, abundance, and sustainability, solar energy has become well recognized and widely utilized [5].

Different researches estimate that covering $0.16 \%$ of the land on earth with $10 \%$ efficient solar conversion systems would provide $20 \mathrm{TW}$ of power, nearly twice the world's consumption rate of fossil energy [6]. This proves the potential of solar energy which in turn points out the necessity of tracking mechanism in solar systems. The tracking mechanism is an electromechanical system that ensures solar radiation is always perpendicular to the surface of the photovoltaic cells (solar cells) which maximizes energy harnessing [7].

Over the years, researchers have developed smart solar trackers for maximizing the amount of energy generation. Before the introduction of solar tracking methods, static solar panels were positioned with a reasonable tilted angle based on the latitude of the location. In this competitive world of 


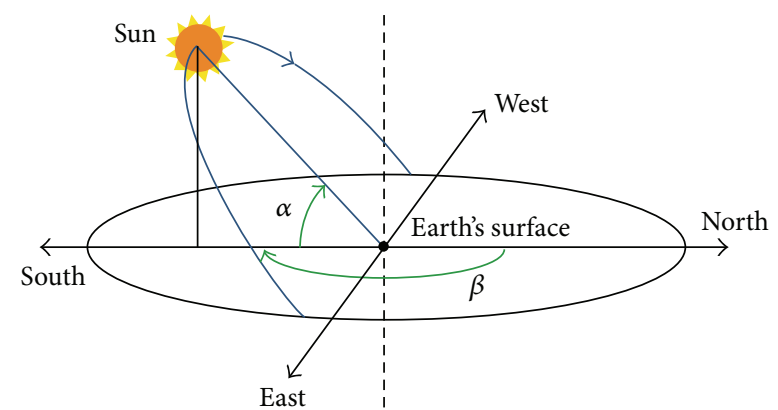

FIGURE 1: Illustration of the solar angles: (a) altitude angle, $\alpha$; (b) azimuthal angle, $\beta$. The solar path corresponds to a day in the early fall or late winter seasons in the northern hemisphere, that is, just prior to the spring equinox or just after the fall equinox. Solar noon is the time of day when $\beta=180$ degree, that is, the sun is directly at south and is halfway between sunrise and sunset.

advanced scientific discoveries, the introductions of automated systems improve existing power generation by $50 \%[8]$.

There are mainly two types of solar trackers on the basis of their movement degrees of freedoms. These are single axis solar tracker and dual axis solar tracker. Again these two systems are further classified on the basis of their tracking technologies. Active, passive, and chronological trackers are three of them $[9,10]$.

Previous researchers used single axis tracking system which follows only the sun's daily motion [11]. But the earth follows a complex motion that consists of the daily motion and the annual motion. The daily motion causes the sun to appear in the east to west direction over the earth whereas the annual motion causes the sun to tilt at a particular angle while moving along east to west direction [12].

Figure 1 shows the daily and annual motion of the sun. The sun's location in the sky relative to a location on the surface of the earth can be specified by two angles as shown in Figure 1. They are (1) the solar altitude angle $(\alpha)$ and (2) the solar azimuth angle $(\beta)$. Angle $\alpha$ is the angle between the sun's position and the horizontal plane of the earth's surface while angle $\beta$ specifies the angle between a vertical plane containing the solar disk and a line running due south [13].

Solar tracking is best achieved when the tilt angle of the solar tracking systems is synchronized with the seasonal changes of the sun's altitude. An ideal tracker would allow the solar modules to point towards the sun, compensating for both changes in the altitude angle of the sun (throughout the day) and latitudinal offset of the sun (during seasonal changes). So the maximum efficiency of the solar panel is not being used by single axis tracking system whereas double axis tracking would ensure a cosine effectiveness of one.

In active tracking or continuous tracking, the position of the sun in the sky during the day is continuously determined by sensors. The sensors will trigger the motor or actuator to move the mounting system so that the solar panels will always face the sun throughout the day. If the sunlight is not perpendicular to the tracker, then there will be a difference in light intensity on one light sensor compared to another. This difference can be used to determine in which direction the tracker has to be tilted in order to be perpendicular to the sun. This method of sun tracking is reasonably accurate except on very cloudy days when it is hard for the sensors to determine the position of the sun in the sky [14].

Passive tracker, unlike an active tracker which determines the position of the sun in the sky, moves in response to an imbalance in pressure between two points at both ends of the tracker. The imbalance is caused by solar heat creating gas pressure on a "low boiling point compressed gas fluid, that is, driven to one side or the other" which then moves the structure. However, this method of sun tracking is not accurate $[15,16]$.

A chronological tracker is a time-based tracking system where the structure is moved at a fixed rate throughout the day as well for different months. Thus the motor or actuator is controlled to rotate at a slow average rate of one revolution per day $\left(15^{\circ}\right.$ per hour). This method of sun tracking is more energy efficient [17].

To track the sun's movement accurately dual axis tracking system is necessary. The active/continuous tracking system tracks the sun for light intensity variation with precision. Hence, the power gain from this system is very high [18]. But to achieve this power gain the system uses two different motors continuously for two different axes. As a result it always consumes a certain amount of extra power compared to time-based tracking system. Therefore to reduce this power loss a combination of active and time-based tracking could be the suitable alternative to this system. Finally the motivation of the research was to design and implement a hybrid dual axis solar tracking system which reduces the motor power consumption while tracking accurately.

A simple energy efficient and rugged tracking model is presented in this paper in order to build a hybrid dual axis solar tracker. To track the sun's daily motion, that is, from east to west direction, a pair of light sensors are used and to track the seasonal motion of the sun real time clock (RTC) is used to create the accurate azimuth angle from some predetermined parameters. The light intensity is compared by microcontroller and it generates the suitable control signals to move the motors in proper direction. So a driver circuit is used to increase the voltage and current level for the operation of the motors. Two full geared stepper motors are used for rotating the solar module in two different axes.

A versatile mechanical system is introduced as a linear actuator to create proper tilt angle. In addition, this linear actuator has high weight lifting capability which is observed experimentally. It is found that energy efficient hybrid dual axis tracking yields almost same energy as continuous dual axis solar tracking system. It is also observed that in hybrid tracking system one motor can remain idle for one month and thus reduces more than $44 \%$ of power consumption as compared with continuous dual axis solar tracking system. This mechanism proved significant benefit of reducing energy consumption by hybrid tracker sacrificing a very little tracking loss. This paper also represents the comparative study between the continuous/active and hybrid solar tracking system. 


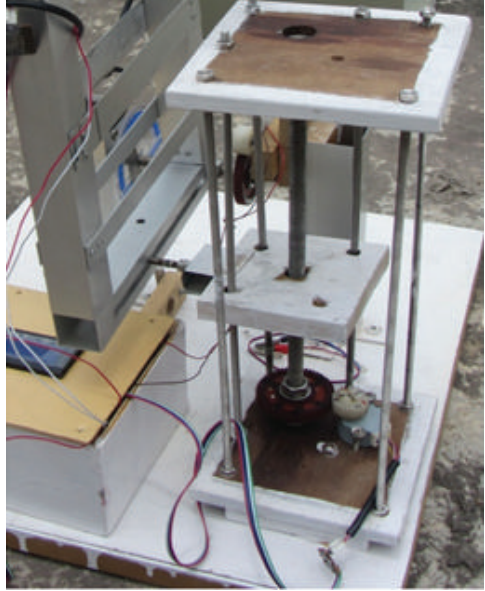

(a)

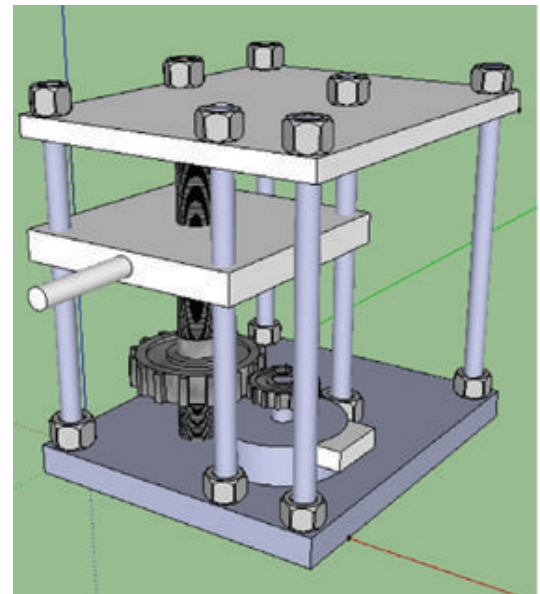

(b)

Figure 2: Design and implementation of linear actuator: (a) implementation and placement of linear actuator with the aluminium body of panel carrier; (b) hardware design of linear actuator in computer aided drafting tool.

\section{Design and Implementation Process}

The whole work involves the reading of different sensor values and then comparing them digitally to determine the exact position of the sun in east-west direction. Again the system is also given some predefined values based on the sun's geographical location in the north-south direction. Overall the entire system can intelligently track the sun's movement both in horizontal and vertical axis. In order to simplify the design and implementation process the whole system is divided into two parts.

These are as follows:
(A) mechanical system design;
(B) electrical circuit design.

(A) Mechanical System Design. Assembling the mechanical system was the most challenging part of this system because the objective was to make an energy efficient solar tracking system which demanded intelligent operations of the tracking motors. Generally one of these motors is used for daily tracking (east-west motion) and other for making a seasonal tracking (north-south motion). So the daily tracking motor operates continuously based on light sensors and the annual motion tracking motor operates only a few times over the year. So for design and implementation process the whole mechanical system is mainly divided into three parts as follows:
(1) linear actuator;
(2) panel carrier;
(3) panel carrier rotator.

(1) Linear Actuator. A linear actuator converts circular motion to a linear vertical motion in contrast to the circular motion of a conventional electric motor. The linear vertical motion is used for creating the seasonal angle of the sun. In this tracking system linear actuator consists of one stepper motor, screw thread, bolt, bearing, circular rod, and some pieces of wood. Figure 2 shows the mechanical design and structure of linear actuator. Experimentally it is found that this mechanical structure has a special feature of high weight lifting using a low power stepper motor.

Linear actuator gives the linear motion in vertical axis (upward and downward) and is connected to one end of panel carrier through a straight single rod hook. The rod hook is attached to the wooden frame. There are some bolts and these are tied with seven 15 -inch long circular rods of $2 \mathrm{~mm}$ diameter. There is also a 13-inch long screw thread and its diameter is $6 \mathrm{~mm}$. A bolt is attached in the middle of the wooden frame and this bolt is also tied with the screw thread. Four circular rods are also mortised through the wooden frame.

The wooden frame moves up and down along with the bolt and the single rod hook. It works in such a way that the wooden frame does not let the bolt move along with the thread screw rather when the thread screw moves then the four circular rods mortised into the wooden frame cause the bolt to move up or down. Now when the single rod hook moves upward or downward it moves along with the panel carrier. The two ends of screw thread are placed in two bearings which helps it to rotate smoothly. These bearings are mortised into the roof and floor. One gear is also placed at the bottom of the screw thread and this gear is connected to the stepper motor gear which is placed on the floor of the linear actuator body. The floor and roof of the linear actuator are made of wood which holds all the linear actuator instruments.

(2) Panel Carrier. Panel carrier is basically a rectangular frame made of aluminum which holds the solar panel with the help of a circular rod. One end of the horizontal base of the panel carrier is attached with the single rod hook of linear actuator and other with the panel carrier rotator. Figure 3 shows the design and implementation of panel carrier. A stepper motor 


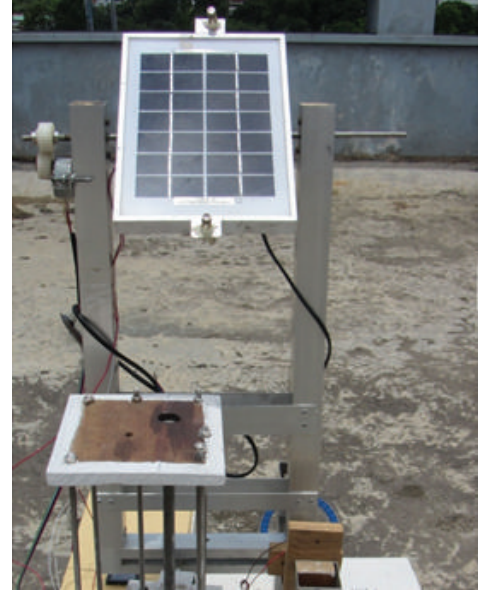

(a)

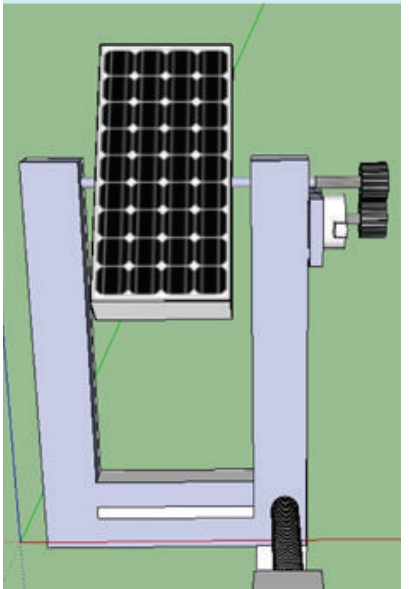

(b)

Figure 3: Design and implementation of panel carrier: (a) implementation and placement of panel carrier with the linear actuator and panel carrier rotator; (b) hardware design of Panel carrier in computer aided drafting tool.

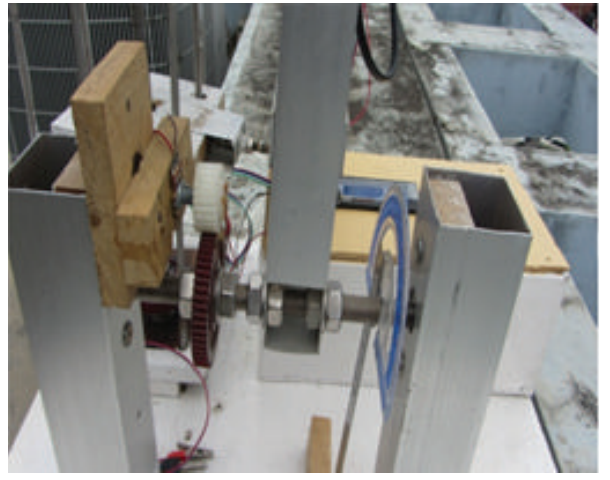

(a)

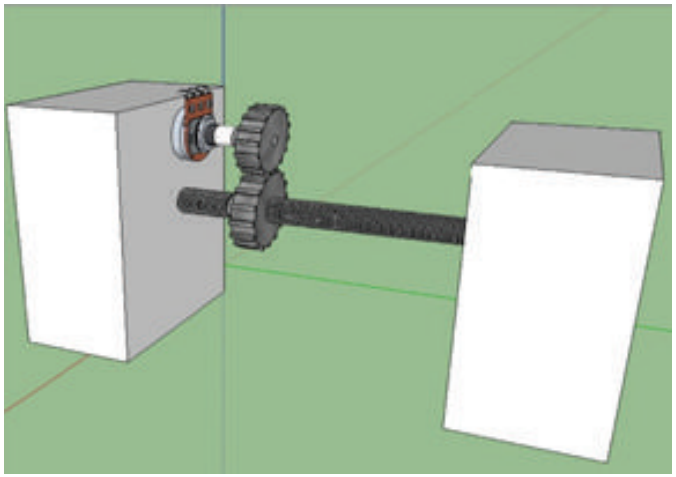

(b)

Figure 4: Design and implementation of panel carrier rotator: (a) implementation and placement of panel carrier rotator with the panel carrier and a wooden base; (b) hardware design of panel carrier rotator in computer aided drafting tool.

with a gear is placed on the body of the aluminium frame. When the stepper motor rotates along with its gear then the panel rotates from east to west by tracking sun's daily motion actively.

The light sensors are placed at the two ends of solar panel. Again the rectangular aluminium frame has a rectangular mortise in its horizontal base. Single circular rod hook from linear actuator goes through this mortise. Thus it helps to lift the panel carrier in a semi-circular path to get sun's tilt angle caused by seasonal/annual motion. While the linear actuator lifts one end of panel carrier the other end needs to be fixed with a panel carrier rotator to get the perfect circular motion.

(3) Panel Carrier Rotator. Panel carrier rotator is used to hold one end of the horizontal base of the solar panel carrier. One screw thread, gear, and position sensors are used in this panel carrier rotator to give a circular movement to the panel carrier. Its base is fixed on a wooden floor. Figure 4 shows the design and implementation of panel carrier rotator and Figure 5 shows the experimental setup of the hybrid dual axis solar tracker.
(B) Electrical Circuit Design. The whole electrical system is mainly divided into three units. These are sensor unit, control unit, and movement adjustment unit. Sensor unit senses three different parameters (light, time, and position) and converts it to appropriate electrical signals. Then the electrical signals from sensor unit are sent to control unit. Control unit determines the direction of the movement of the motors both in the horizontal and vertical axes. Finally the movement adjustment unit adjusts the position of the solar module by receiving signal from the control unit. This adjustment is done by using two geared unipolar stepper motors. Figure 6 shows the overall block diagram of the whole system.

(1) Sensor Unit. The sensor unit consists of three sensor circuits. These are as follows:
(a) light sensor;
(b) real time clock;
(c) position sensor. 


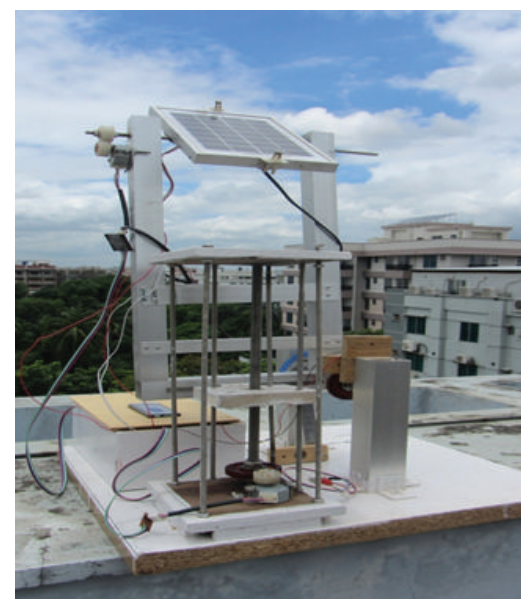

FIgURE 5: Experimental setup of the Hybrid dual axis solar tracker.

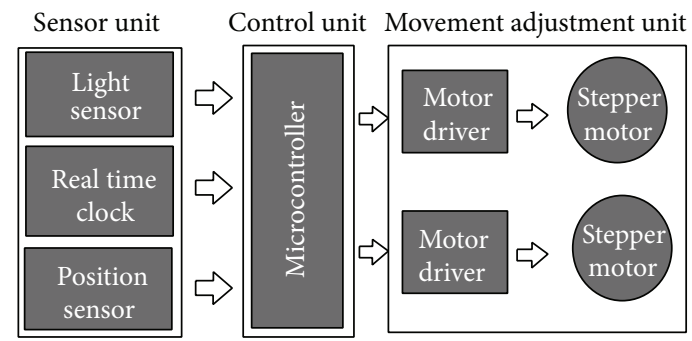

FIGURE 6: Block diagram of the electrical circuit.

(a) Light Sensor. Light sensors are used for measuring light intensity and generating a corresponding analog voltage signal into the input of the analog to digital converter of the microcontroller. Since this is a hybrid dual axis solar tracking system so, to track the sun's daily motion continuously, that is, from east to west, a pair of light dependent resistors (LDR) is used as light sensors. On the other hand, the sun's annual motion, that is, from north to south, is tracked by the real time clock (RTC) device and position sensor.

A light dependent resistor (LDR) is a resistor whose resistance decreases with increasing incident light intensity. Figure 7 shows the basic LDR circuit and Table 1 shows the different specifications of LDR used in the tracking system [19]. The relationship between the resistance $R_{\mathrm{LDR}}$ (resistance of LDR) and light intensity (Lux) for a typical LDR is given in following equation [20]:

$$
R_{\mathrm{LDR}}=\left(\frac{500}{\mathrm{Lux}}\right) \mathrm{k} \Omega
$$

where $R_{\mathrm{LDR}}=$ Resistance of LDR.

(b) Real Time Clock. Real time clock is a clock device that keeps track of the current time. There are different types of real time clock (RTC) device; among them DS1307 is used here. This is a battery-backed real time clock (RTC), that is, connected to microcontroller via $\mathrm{I} 2 \mathrm{C}$ bus to keep track of time even if it is reprogrammed or if the power is lost.

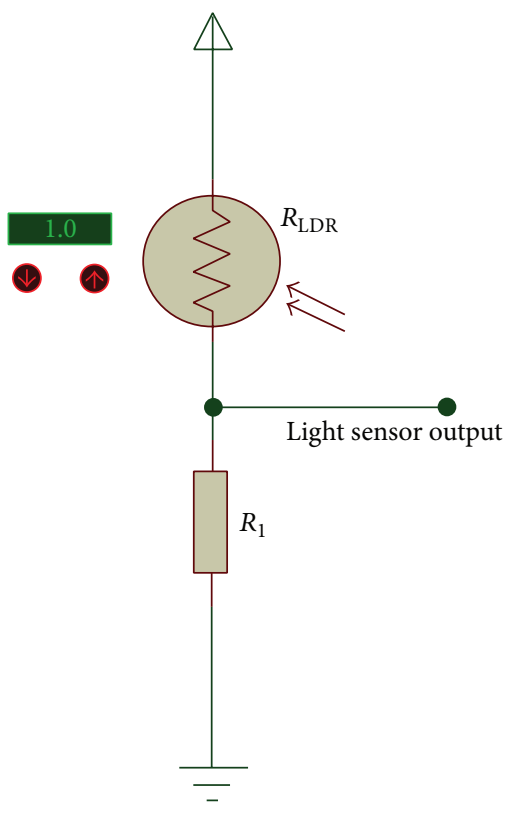

FIGURE 7: Basic LDR circuit.

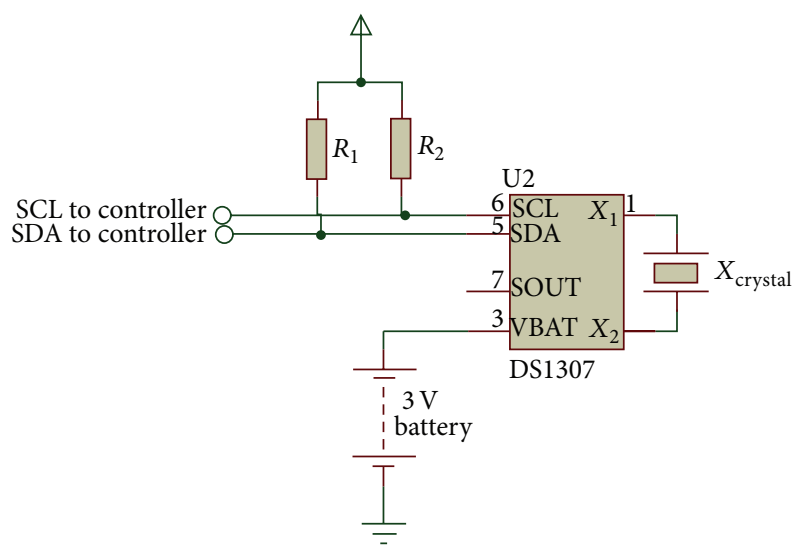

FIGURE 8: Real time clock circuit.

This device is suitable for data logging, clock-building, time stamping, timers, alarms, and so forth. Microcontroller takes the month and hour values from the RTC device to track the sun's annual motion and the darkness of night to take the solar panel at its initial position. Figure 8 shows the basic RTC circuit. In the figure U2 is the RTC chip. Address and data from RTC chip are transferred serially through an I2C, bidirectional bus. The two I2C signals are serial data (SDA) and serial clock (SCL) and these two signals are sent to controller with two pull-up resistors $R_{1}$ and $R_{2}$. Together, these signals make it possible to support serial transmission of 8 bit bytes of data- 7 bit device addresses plus control bits-over the two-wire serial bus. $X_{\text {crystal }}$ is a $32.768 \mathrm{kHz}$ quartz crystal used for required clock generation for RTC chip And B1 is a 3-volt battery used for power backup in case of power failure.

(c) Position Sensor. Position sensor detects the sun's annual motion. A variable resistor is used here as position sensor. 
TABLE 1: Specification of LDR.

\begin{tabular}{lccccc}
\hline $\begin{array}{l}\text { Dark resistance } \\
(\mathrm{M} \Omega)\end{array}$ & $\begin{array}{c}\text { Illuminated resistance } \\
(\mathrm{k} \Omega)\end{array}$ & $\begin{array}{c}\text { Sensitivity } \\
(\Omega / \mathrm{lux})\end{array}$ & $\begin{array}{c}\text { Spectral application range } \\
(\mathrm{nm})\end{array}$ & $\begin{array}{c}\text { Rise time } \\
(\mathrm{ms})\end{array}$ & $\begin{array}{c}\text { Fall time } \\
(\mathrm{ms})\end{array}$ \\
\hline 20 & $5-20$ & 0.9 & $400-700$ & 70 & 15 \\
\hline
\end{tabular}

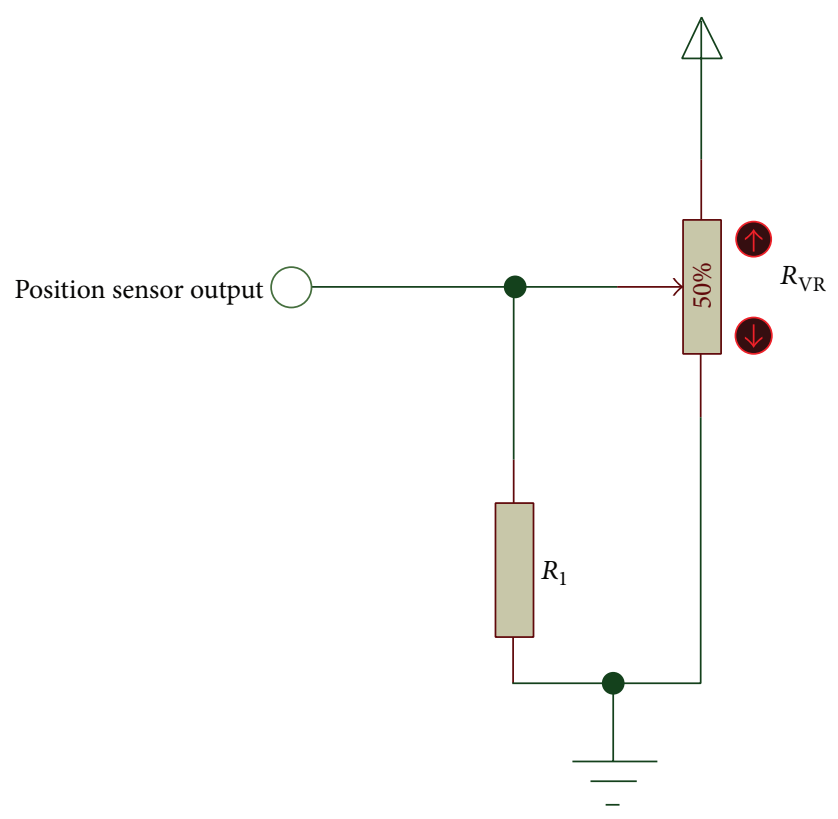

FIgURE 9: Position sensor circuit.

Figure 9 shows a variable resistor connected to another resistor $R_{1}$. So when the resistivity of variable resistor changes the position sensor output also changes. The output from this circuit goes to controller and different voltages in the output of position sensor circuit represent different latitude angle of the sun for its annual motion.

Position sensor is placed in the panel carrier rotator. When linear actuator moves linearly then panel carrier rotator rotates a semicircular path which causes the position sensor to change its voltage level. The panel carrier rotator rotates $50^{\circ}$ degree in a semicircular path with respect to the horizontal axis as in the experimental location sun's latitude angle changes in between this $50^{\circ}$. The panel carrier rotator can rotate $75^{\circ}$ in both sides which may also be applicable in other locations. In that case the sensor has to be calibrated accurately. For 12 months different 12 values of sun's latitude angle are predetermined and set in the microcontroller and with respect to these values microcontroller decides how much to move the linear actuator. Panel carrier rotator rotates due to the linear actuator's linearly upward and downward motion with the panel carrier. A gear is placed with the panel carrier rotator which also rotates with it. This gear rotation causes the variable resistor's gear to rotate and this is how the resistivity of the variable resistor changes. Thus the signal is changing from the position sensor.

(2) Control Unit. Microcontroller is the main control unit of this whole system. The output from the sensor unit comes to the input of the microcontroller which determines the direction of the movement of the motors both in the horizontal and vertical axes. For this research ATmega32 microcontroller is used. This is from the Atmel AVR family. Figure 10 shows the main flowchart of the microcontroller programming. Figure 11 shows another flowchart of the microcontroller programming which is a part of the main flowchart showed in Figure 10.

(3) Movement Adjustment Unit. Movement adjustment unit consists of two geared unipolar stepper motors along with their motor driver device. The output from microcontroller is sent to the motor driver which executes the proper sequence to turn the stepper motors in the required direction. To run the unipolar stepper motor in full drive or half drive mode ULN2803 is used as motor driver IC. This driver is an array of eight Darlington transistors. Darlington pair is a single transistor with a high current gain. Thus the current gain is required for motor drive and it reduces the circuit space and complexity. Figure 12 shows the unipolar stepper motor, motor driver device, and Darlington pair.

The two full geared stepper motors are used here for the accurate tracking of the sun. For our experimental purpose a small scale system was implemented for 3-watt solar panel. The specifications of solar panel and gear and stepper motors are listed as follows.

Specifications of solar panel as load of the motor:

$$
\text { mass of solar panel, } m=0.75 \mathrm{Kg} \text {; }
$$




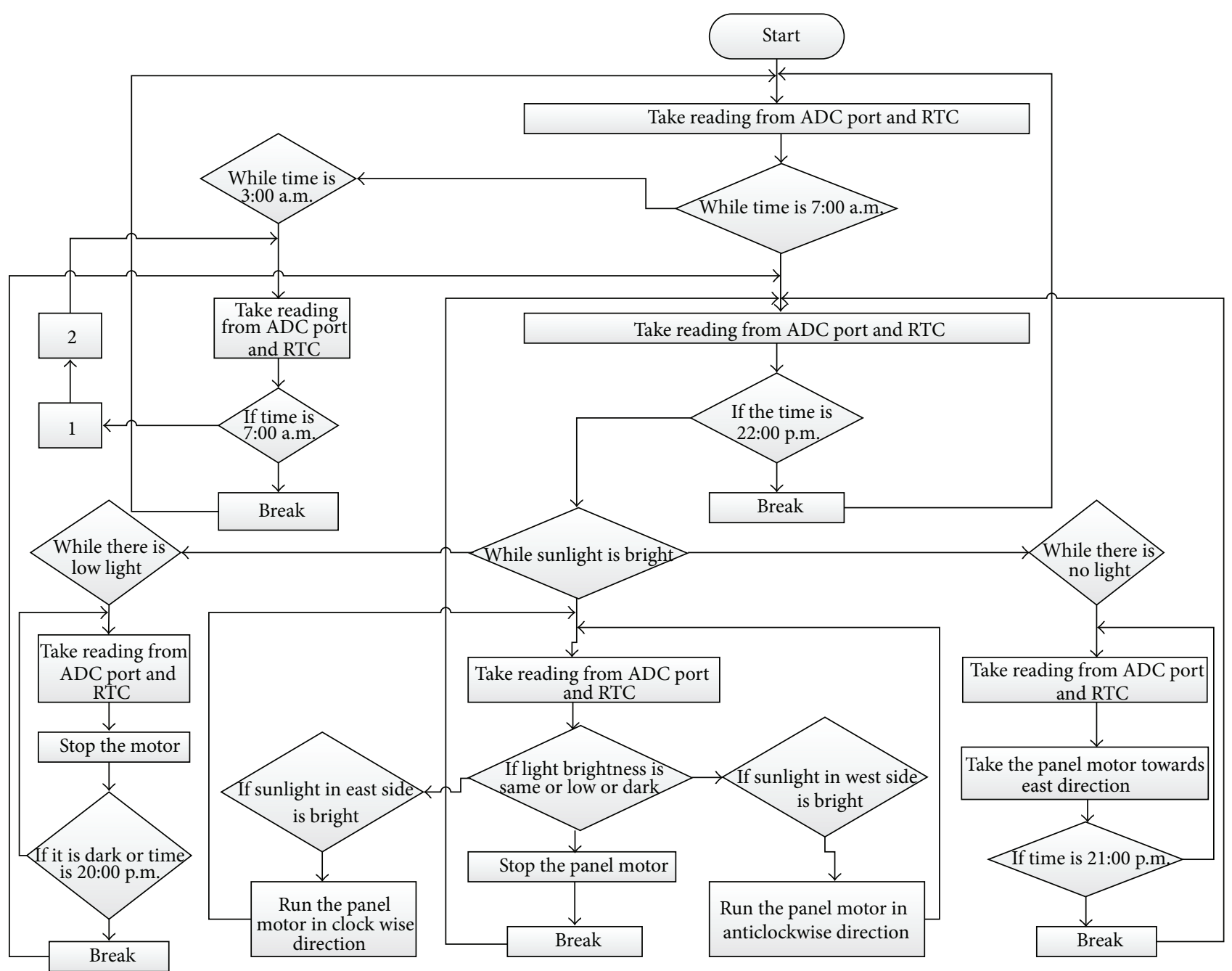

FIGURE 10: Main flowchart of microcontroller programming.

length of solar panel, $L=0.165 \mathrm{~m}$;

width of solar panel, $D=0.23 \mathrm{~m}$;

height of solar panel, $H=0.015 \mathrm{~m}$;

volume of solar panel, $v=L \times D \times H=5.69 \times 10^{-4} \mathrm{~m}^{3}$;

density, $\rho=(m / v)=1318.10 \mathrm{~kg} \cdot \mathrm{m}^{-3}$.

Specifications of gears:

number of gear teeth, $N 1=N 2=24$;

mass of gear, $m_{G 1}=m_{G 2}=5 \times 10^{-3} \mathrm{~kg}$;

diameter of gear, $D_{G 1}=D_{G 2}=0.027 \mathrm{~m}$.

Specifications of motor:

inertia of motor, $J_{m} \approx 0$;

pull-out torque $=0.147 \mathrm{~N} \cdot \mathrm{m}$;

pull-out frequency, $f=100 \mathrm{~Hz}$;

friction coefficient, $\mu=0.05$; step angle, $\theta_{s}=0.044^{\circ}$;

angle coefficient, $n=3.6^{\circ} / \theta_{s}=81.81$.

For the pull-out frequency of $100 \mathrm{~Hz}$ the required motor torque to rotate the panel is calculated as follows [21-23].

Calculation of moment of inertia is given as follows:

Inertia of the load is

$$
J_{L}=\frac{\pi}{32} \times \rho \times L \times D^{4} \times\left(\frac{N 2}{N 1}\right)^{2}=0.0597 \mathrm{~kg} \cdot \mathrm{m}^{2},
$$

inertia of gear 1 is

$$
J_{G 1}=\frac{1}{8} \times m_{G 1} \times D_{G 1}^{2} \times\left(\frac{N 2}{N 1}\right)^{2},
$$

inertia of gear 2 is

$$
J_{G 2}=\frac{1}{8} \times m_{G 2} \times D_{G 2}{ }^{2},
$$

number of gear teeth, $N 1=N 2$ so,

$$
J_{G 1}=J_{G 2}=\frac{1}{8} \times m_{G 2} \times D_{G 2}{ }^{2}=4.56 \times 10^{-7} \mathrm{~kg} \cdot \mathrm{m}^{2} .
$$




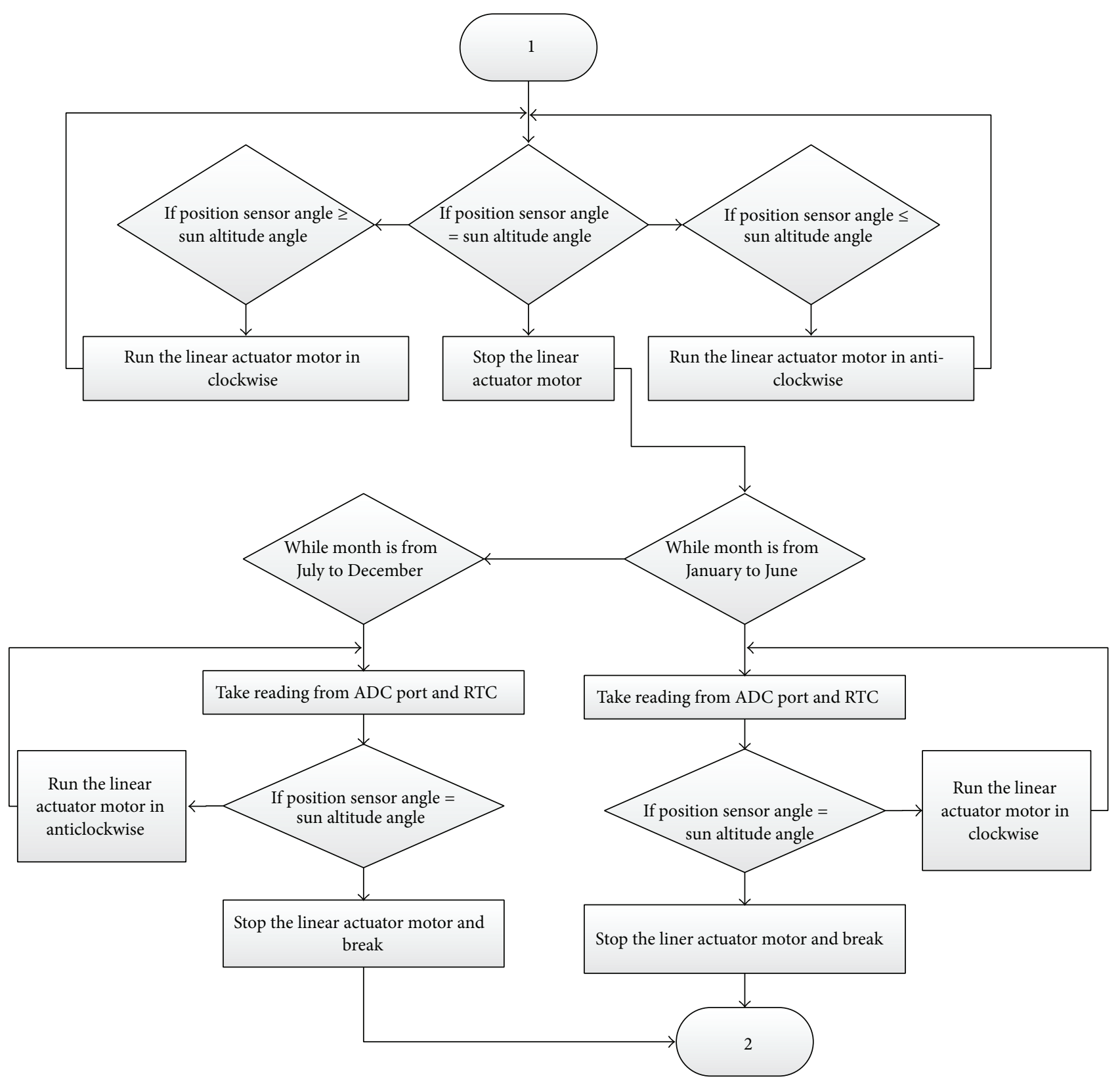

FIGURE 11: Continuation of main flowchart of microcontroller programming.

So, inertia of the system is

$$
J_{T}=J_{L}+J_{G 1}+J_{G 2}+J_{m}=0.0597 \mathrm{~kg} \cdot \mathrm{m}^{2} .
$$

Calculation of acceleration torque is given as follows.

Now, acceleration torque is

$$
T_{a}=J_{T} \times \frac{\pi \times \theta_{s}}{180 \times n} \times f^{2}=5.60 \times 10^{-3} \mathrm{~N} \cdot \mathrm{m} .
$$

Force to rotate the load is

$$
F=m \times g(\sin \theta+\mu \times \cos \theta)=0.3675 \mathrm{~N} \cdot \mathrm{m} .
$$

Calculation of load torque is given as follows.

Now, load torque is

$$
T_{L}=\frac{F \times D}{2}+T_{F}=0.0423 \mathrm{~N} \cdot \mathrm{m} ;
$$

here, load torque due to friction, $T_{F} \approx 0$.

Calculation of required motor torque is given as follows. Total calculated torque is

$$
T_{T}=T_{a}+T_{L}=0.0479 \mathrm{~N} \cdot \mathrm{m}
$$




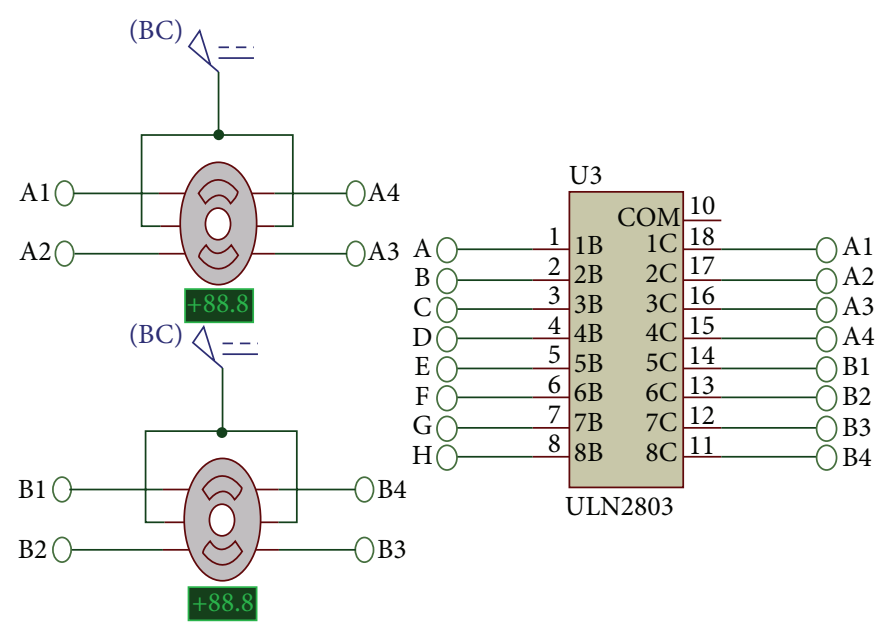

(a)

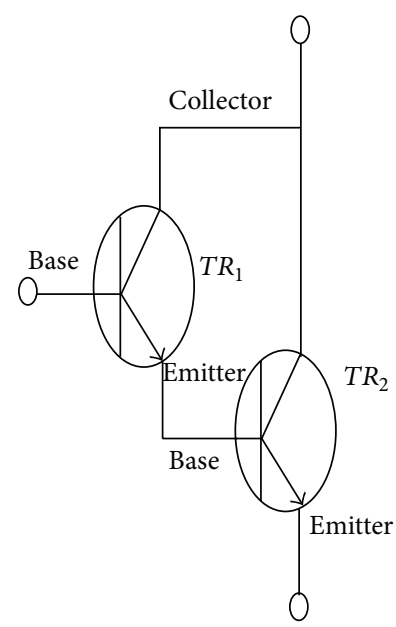

(b)

FIGURE 12: Movement adjustment unit: (a) the unipolar stepper motor and motor driver device (ULN2803) and (b) Darlington pair.

Required motor torque is

$$
T_{M}=K_{s} \times T_{T}=0.0958 \mathrm{~N} \cdot \mathrm{m} .
$$

Here, safety factor, $K_{s}=2$.

$\therefore$ Required motor torque $<$ pull-out torque.

So from the above comparison it is clear that pull-out torque of $0.147 \mathrm{~N} \cdot \mathrm{m}$. of stepper motor is sufficient enough to rotate the solar panel of $0.75 \mathrm{~kg}$.

\section{Experimental Results and Data Analysis}

(A) Comparative Study of Solar Panel Power Output. All the experiments have been conducted in Dhaka, Bangladesh $\left(23^{\circ} 42^{\prime} 0^{\prime \prime} \mathrm{N} 90^{\circ} 22^{\prime} 30^{\prime \prime} \mathrm{E}\right)$. Table 2 shows the current and voltage values received from the static panel, hybrid tracking system, and continuous tracking system for different times in a day. From Table 2 it is seen that at 8:00 am there is much improvement in current by both the tracking systems compared to the static panel. But as time goes on the difference in current among these three systems decreases up to around 11:00 am. After that when the sun rotates more towards west this difference increases again. The highest current of static panel, hybrid tracking system, and continuous tracking system is $0.47 \mathrm{amp}, 0.48 \mathrm{amp}$, and $0.50 \mathrm{amp}$, respectively, at 12:30 pm. But in case of voltage the variation is less compared to current as the voltage has no direct relation with the sun light intensity. Figure 13 shows the comparison of current versus time curves for the static panel, hybrid tracking system, and continuous tracking system.

Table 3 shows the power values of the static panel and both the tracking systems. The power gain of tracking systems over static panel and between the two tracking systems for different times is also given in Table 3. The maximum power output of the static panel, hybrid tracking system, and continuous tracking system is found as 3.7036 watt, 3.7824 watt, and 3.94 watt, respectively at 12:30 pm. Much more power gain is achieved in the morning and afternoon because both the tracking systems can accurately track the

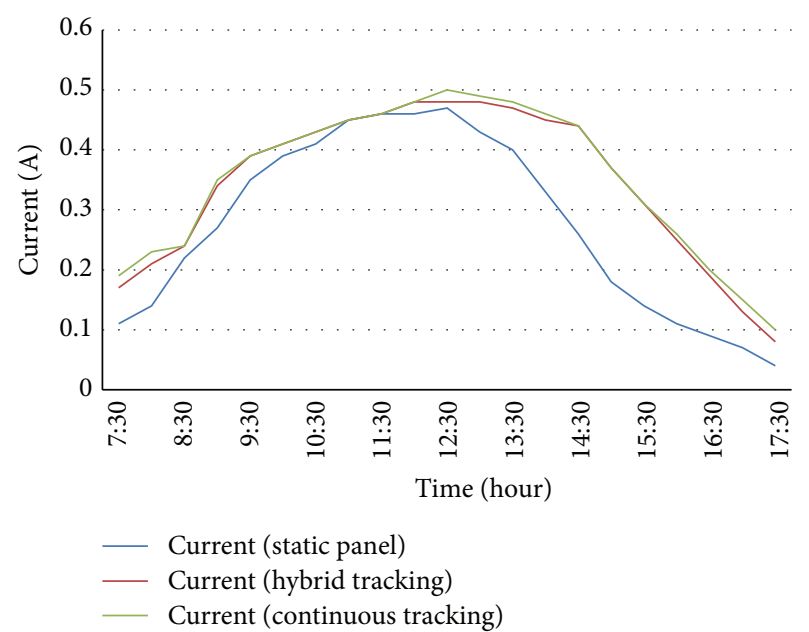

FIGURE 13: Comparison curve: comparison of current versus time curve for the static panel, hybrid tracking system, and continuous tracking system.

sun at these times while the static system cannot. For all these technologies power fall was very fast from $3: 30 \mathrm{pm}$ to $5: 30 \mathrm{pm}$ because of the low duration of day light.

The total power of static panel, hybrid tracking system, and the continuous tracking system throughout the day is 45.21 watt, 56.69 watt, and 58.24 watt, respectively. So the average power gain of hybrid tracking system over the static panel is $25.62 \%$. Similarly the average power gain of continuous tracking system over the static panel is $28.10 \%$ and over the hybrid tracking system is $4.19 \%$.

(B) Comparison of Stepper Motor Power Consumption. The power consumption by the stepper motors in both the solar tracking system is not same. Table 4 shows the comparison of stepper motors power consumption between the two tracking systems. 
TABLE 2: Current and voltage values of static and tracking panel at different times in a day.

\begin{tabular}{|c|c|c|c|c|c|c|}
\hline \multirow{2}{*}{$\begin{array}{l}\text { Time } \\
\text { (hour) }\end{array}$} & \multicolumn{2}{|c|}{ Static panel } & \multicolumn{2}{|c|}{ Hybrid tracking system } & \multicolumn{2}{|c|}{ Continuous tracking system } \\
\hline & $\begin{array}{c}\text { Current } \\
\text { (ampere) }\end{array}$ & $\begin{array}{l}\text { Voltage } \\
\text { (volt) }\end{array}$ & $\begin{array}{l}\text { Current } \\
\text { (ampere) }\end{array}$ & $\begin{array}{l}\text { Voltage } \\
\text { (volt) }\end{array}$ & $\begin{array}{l}\text { Current } \\
\text { (ampere) }\end{array}$ & $\begin{array}{l}\text { Voltage } \\
\text { (volt) }\end{array}$ \\
\hline $7: 30$ & 0.11 & 7.82 & 0.17 & 7.82 & 0.19 & 7.92 \\
\hline 8:00 & 0.14 & 7.82 & 0.21 & 7.82 & 0.23 & 7.92 \\
\hline $8: 30$ & 0.22 & 7.83 & 0.24 & 7.83 & 0.24 & 7.9 \\
\hline 9:00 & 0.27 & 7.9 & 0.34 & 8 & 0.35 & 8 \\
\hline $9: 30$ & 0.35 & 7.93 & 0.39 & 7.98 & 0.39 & 7.98 \\
\hline $10: 00$ & 0.39 & 7.92 & 0.41 & 7.92 & 0.41 & 7.92 \\
\hline $10: 30$ & 0.41 & 7.88 & 0.43 & 7.92 & 0.43 & 7.92 \\
\hline 11:00 & 0.45 & 7.88 & 0.45 & 7.88 & 0.45 & 7.88 \\
\hline 11:30 & 0.46 & 7.88 & 0.46 & 7.88 & 0.46 & 7.88 \\
\hline $12: 00$ & 0.46 & 7.88 & 0.48 & 7.88 & 0.48 & 7.88 \\
\hline $12: 30$ & 0.47 & 7.88 & 0.48 & 7.88 & 0.5 & 7.88 \\
\hline $13: 00$ & 0.43 & 7.88 & 0.48 & 7.88 & 0.49 & 7.88 \\
\hline $13: 30$ & 0.4 & 7.77 & 0.47 & 7.81 & 0.48 & 7.81 \\
\hline $14: 00$ & 0.33 & 7.79 & 0.45 & 7.83 & 0.46 & 7.93 \\
\hline $14: 30$ & 0.26 & 7.71 & 0.44 & 7.71 & 0.44 & 7.83 \\
\hline $15: 00$ & 0.18 & 7.63 & 0.37 & 7.76 & 0.37 & 7.9 \\
\hline $15: 30$ & 0.14 & 7.54 & 0.31 & 7.7 & 0.31 & 7.86 \\
\hline $16: 00$ & 0.11 & 7.52 & 0.25 & 7.73 & 0.26 & 7.86 \\
\hline $16: 30$ & 0.09 & 7.41 & 0.19 & 7.71 & 0.2 & 7.71 \\
\hline $17: 00$ & 0.07 & 7.39 & 0.13 & 7.65 & 0.15 & 7.71 \\
\hline $17: 30$ & 0.04 & 7.33 & 0.08 & 7.5 & 0.1 & 7.64 \\
\hline
\end{tabular}

TABLE 3: Power values of static and tracking panel and the corresponding power gain by tracking panel over static panel at different times in a day.

\begin{tabular}{|c|c|c|c|c|c|c|}
\hline \multirow[t]{2}{*}{$\begin{array}{l}\text { Time } \\
\text { (hour) }\end{array}$} & Static panel & $\begin{array}{c}\text { Hybrid } \\
\text { tracking panel }\end{array}$ & $\begin{array}{l}\text { Continuous } \\
\text { tracking panel }\end{array}$ & $\begin{array}{c}\text { Power gain by } \\
\text { hybrid tracking system } \\
\text { over static panel }\end{array}$ & $\begin{array}{c}\text { Power gain by } \\
\text { continuous tracking system } \\
\text { over static panel }\end{array}$ & $\begin{array}{c}\text { Power gain by } \\
\text { continuous tracking system } \\
\text { over hybrid tracking system }\end{array}$ \\
\hline & $\begin{array}{l}\text { Power } \\
\text { (watt) }\end{array}$ & $\begin{array}{l}\text { Power } \\
\text { (watt) }\end{array}$ & $\begin{array}{l}\text { Power } \\
\text { (watt) }\end{array}$ & $\%$ & $\%$ & $\%$ \\
\hline $7: 30$ & 0.8602 & 1.3294 & 1.5048 & 35.29412 & 42.83626 & 11.65603 \\
\hline 8:00 & 1.0948 & 1.6422 & 1.8216 & 33.33333 & 39.89899 & 11.65603 \\
\hline $8: 30$ & 1.7226 & 1.8792 & 1.896 & 8.333333 & 9.14557 & 9.848485 \\
\hline 9:00 & 2.133 & 2.72 & 2.8 & 21.58088 & 23.82143 & 0.886076 \\
\hline $9: 30$ & 2.7755 & 3.1122 & 3.1122 & 10.81871 & 10.81871 & 2.857143 \\
\hline 10:00 & 3.0888 & 3.2472 & 3.2472 & 4.878049 & 4.878049 & 0 \\
\hline $10: 30$ & 3.2308 & 3.4056 & 3.4056 & 5.132723 & 5.132723 & 0 \\
\hline 11:00 & 3.546 & 3.546 & 3.546 & 0 & 0 & 0 \\
\hline 11:30 & 3.6248 & 3.6248 & 3.6248 & 0 & 0 & 0 \\
\hline $12: 00$ & 3.6248 & 3.7824 & 3.7824 & 4.166667 & 4.166667 & 0 \\
\hline $12: 30$ & 3.7036 & 3.7824 & 3.94 & 2.083333 & 12.2449 & 0 \\
\hline 13:00 & 3.3884 & 3.7824 & 3.8612 & 10.41667 & 12.2449 & 4 \\
\hline $13: 30$ & 3.108 & 3.6707 & 3.7488 & 15.3295 & 17.09347 & 2.040816 \\
\hline 14:00 & 2.5707 & 3.5235 & 3.6478 & 27.04129 & 29.52739 & 2.083333 \\
\hline $14: 30$ & 2.0046 & 3.3924 & 3.4452 & 40.90909 & 41.8147 & 3.407533 \\
\hline $15: 00$ & 1.3734 & 2.8712 & 2.923 & 52.16634 & 53.01403 & 1.532567 \\
\hline $15: 30$ & 1.0556 & 2.387 & 2.4366 & 55.77713 & 56.67734 & 1.772152 \\
\hline $16: 00$ & 0.8272 & 1.9325 & 2.0436 & 57.19534 & 59.52241 & 2.035623 \\
\hline $16: 30$ & 0.6669 & 1.4649 & 1.542 & 54.47471 & 56.75097 & 5.436485 \\
\hline $17: 00$ & 0.5173 & 0.9945 & 1.1565 & 47.98391 & 55.27021 & 5 \\
\hline $17: 30$ & 0.2932 & 0.6 & 0.764 & 51.13333 & 61.62304 & 14.00778 \\
\hline
\end{tabular}


TABLE 4: Comparison of stepper motor power consumption.

\begin{tabular}{lccc}
\hline & Hybrid tracking system & \multicolumn{2}{c}{ Continuous tracking system } \\
$\begin{array}{l}\text { Power consumption } \\
\text { for movement in east to west }\end{array}$ & $\begin{array}{c}\text { Power consumption } \\
\text { for movement in north to south }\end{array}$ & $\begin{array}{c}\text { Power consumption } \\
\text { for movement in east to west }\end{array}$ & $\begin{array}{c}\text { Power consumption } \\
\text { for movement in north to south }\end{array}$ \\
\hline $\begin{array}{l}0.6 \mathrm{watt} \\
\text { Total }=0.6 \mathrm{watt}\end{array}$ & $0.6 \mathrm{watt}$ & $0.48 \mathrm{watt}$ \\
\hline
\end{tabular}

So power saved by hybrid tracking system over continuous tracking system is $44.44 \%$.

(C) Data Analysis. So from all these data it is seen that the hybrid dual axis tracking system has average power generation of 56.69 watt whereas the continuous tracking system has 58.24 watt. Therefore continuous tracking system has only $4.2 \%$ average power gain over hybrid dual axis tracking system. On the other hand hybrid dual axis tracking system is saving $44.44 \%$ system power consumption compared to continuous tracking system. Though the continuous tracking system gives a slight improvement in power gain, due to its continuous tracking, it consumes much more power compared to the hybrid dual axis tracking system. Considering the case of $44.44 \%$ power saving by hybrid tracking system, it can be concluded that the hybrid dual axis tracking system can operate much more efficiently compared to the continuous tracking system while sacrificing little about $4.2 \%$ tracking accuracy.

\section{Conclusion}

The design, implementation, and testing of a hybrid dual axis solar tracking system is presented in the study. The Performance of the developed system was experimented and compared with both the static and continuous dual axis solar tracking system. This work demonstrates that hybrid dual axis solar tracking system can assure higher power generation compared to static panel as well as less power consumption compared to continuous dual axis solar tracking system. The result shows that the hybrid dual axis tracking system has $25.62 \%$ more average power gain over static system while it has $4.2 \%$ less average power gain compared to continuous tracking system. In hybrid dual axis solar tracking system one motor runs continuously to track continuous movement of sun due to daily motion and another motor runs once in a month to track suns seasonal motion. But in other trackers like in continuous solar tracker it needs to move both the motors continuously. Thus the hybrid system is saving motor power consumption while the power gain compared to other technology is almost marginal. So further comparative study about stepper motor power consumption shows that hybrid tracking system can save $44.44 \%$ power compared to continuous tracking system. This amount of power saving will have a significant effect in large systems like heliostat power plants where a lot of trackers are required and power saved by all the systems will show a big amount of power. Other than this the designed tracking system can also be implemented for the solar thermal systems. Finally the proposed design is achieved with low power consumption, high accuracy, and low cost.

\section{Conflict of Interests}

The authors declare that there is no conflict of interests regarding the publication of this paper.

\section{Acknowledgment}

The authors thank M.D. Ahasanul Kabir of American International University, Bangladesh (AIUB), for his help with the mechanical system implementation.

\section{References}

[1] G. Deb and A. B. Roy, "Use of solar tracking system for extracting solar energy," International Journal of Computer and Electrical Engineering, vol. 4, no. 1, pp. 42-46, 2012.

[2] T. Tudorache and L. Kreindler, "Design of a solar tracker system for PV power plants," Acta Polytechnica Hungarica, vol. 7, no. 1, pp. 23-39, 2010.

[3] C.-L. Shen and C.-T. Tsai, "Double-linear approximation algorithm to achieve maximum-power-point tracking for photovoltaic arrays," Energies, vol. 5, no. 6, pp. 1982-1997, 2012.

[4] K. Liu, "Dynamic characteristics and graphic monitoring design of photovoltaic energy conversion system," WSEAS Transactions on Systems, vol. 10, no. 8, pp. 239-248, 2011.

[5] T. Tudorache, C. D. Oancea, and L. Kreindler, "Performance evaluation of a solar tracking PV panel," U.P.B. Scientific Bulletin, Series C: Electrical Engineering, vol. 74, no. 1, pp. 3-10, 2012.

[6] H. Mousazadeh, A. Keyhani, A. Javadi, H. Mobli, K. Abrinia, and A. Sharifi, "A review of principle and sun-tracking methods for maximizing solar systems output," Renewable and Sustainable Energy Reviews, vol. 13, no. 8, pp. 1800-1818, 2009.

[7] M. Benghanem, "Optimization of tilt angle for solar panel: Case study for Madinah, Saudi Arabia," Applied Energy, vol. 88, no. 4, pp. 1427-1433, 2011.

[8] C. Praveen, "Design of automatic dual-axis solar tracker using microcontroller," in Proceedings of the International Conference on Computing and Control Engineering (ICCCE '12), April 2012.

[9] D. F. Fam, S. P. Koh, S. K. Tiong, and K. H. Chong, "Qualitative analysis of stochastic operations in dual axis solar tracking environment," Research Journal of Recent Sciences, vol. 1, no. 9, pp. 74-78, 2012.

[10] A. M. Sharan and M. Prateek, "Automation of minimum torquebased accurate solar tracking systems using microprocessors," 
Journal of the Indian Institute of Science, vol. 86, no. 5, pp. 415437, 2006.

[11] C. Alexandru and M. Comsit, Virtual Prototyping of the Solar Tracking Systems, Department of Product Design and Robotics, University Transilvania of Braşov, Brasov, Romania.

[12] A. Hsing, Solar Panel Tracker, Senior Project, Electrical Engineering Department, California Polytechnic State University, San Luis Obispo, Calif, USA, 2010.

[13] N. A. Kelly and T. L. Gibson, "Increasing the solar photovoltaic energy capture on sunny and cloudy days," Solar Energy, vol. 85, no. 1, pp. 111-125, 2011.

[14] M. B. Omar, Low Cost Solar Tracker, Faculty of Electrical \& Electronics Engineering, Universiti Malaysia Pahang, 2009.

[15] A. Argeseanu, E. Ritchie, and K. Leban, "New low cost structure for dual axis mount solar tracking system using adaptive solar sensor," in Proceedings of the 12th International Conference on Optimization of Electrical and Electronic Equipment (OPTIM '10), pp. 1109-1114, Braşov, Romania, May 2010.

[16] M. J. Clifford and D. Eastwood, "Design of a novel passive solar tracker," Solar Energy, vol. 77, no. 3, pp. 269-280, 2004.

[17] N. Barsoum, "Fabrication of dual-axis solar tracking controller project," Intelligent Control and Automation, vol. 2, no. 2, pp. 57-68, 2011.

[18] S. Rahman, R. A. Ferdaus, M. Abdul Mannan, and M. A. Mohammed, "Design \& implementation of a dual axis solar tracking system," American Academic \& Scholarly Research Journal, vol. 5, no. 1, pp. 47-54, 2013.

[19] CdS Photoconductive Photocells, Advanced Photonix, http:// www.cooking-hacks.com/skin/frontend/default/cooking/pdf/ LDR-Datasheet.pdf.

[20] "Measure Light Intensity using Light Dependent Resistor (LDR)," http://www.emant.com/316002.page.

[21] Motor torque calculation, Leadshine technology, http://www .leadshine.com/Pdf/Calculation.pdf.

[22] "Selecting a stepping motor, Oriental motor," http://www.oriental-motor.co.uk/media/files/17112005105315.pdf.

[23] Technical reference, Oriental motor, http://www.orientalmotor .com/products/pdfs/2012-2013/G/usa_tech_calculation.pdf. 


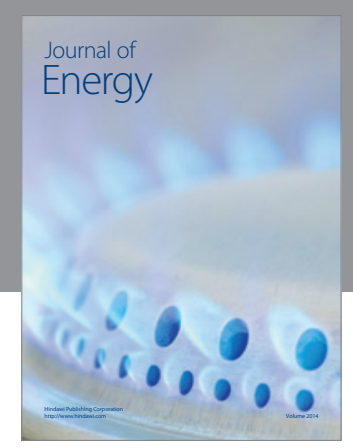

Journal of

Industrial Engineering
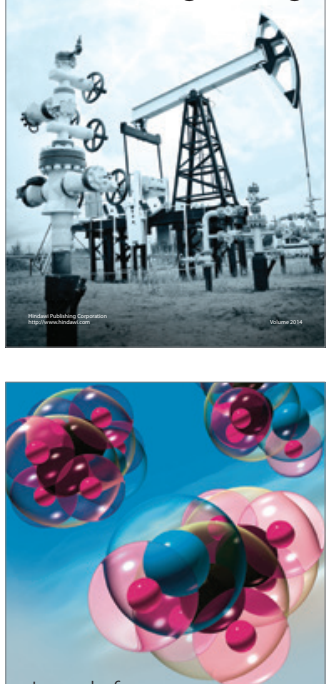

Fuels
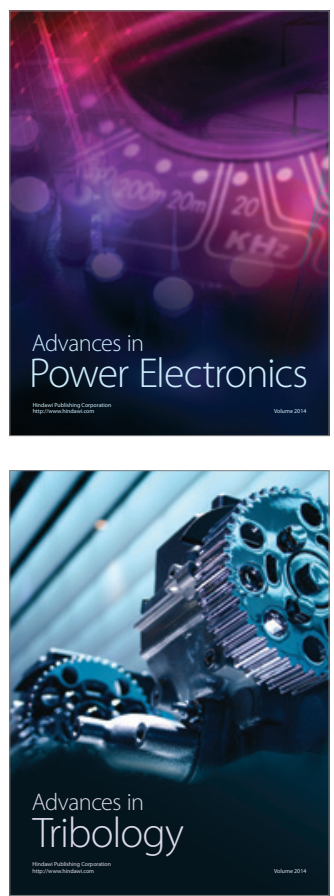

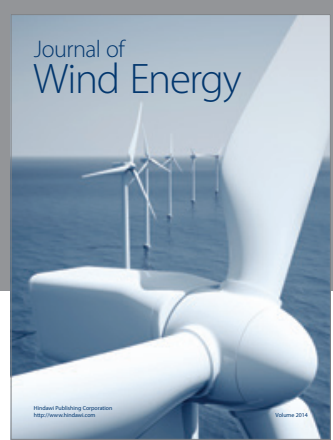

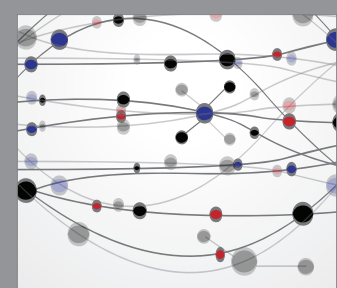

The Scientific World Journal

Submit your manuscripts at http://www.hindawi.com

Journal of

Structures
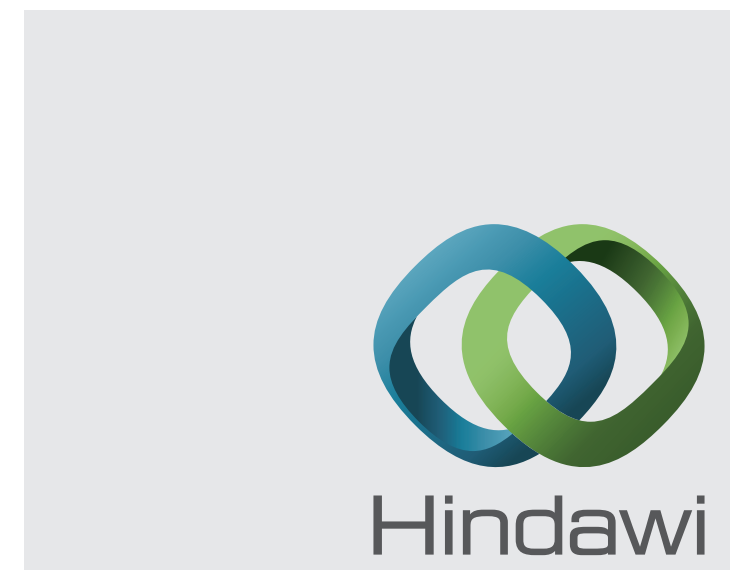

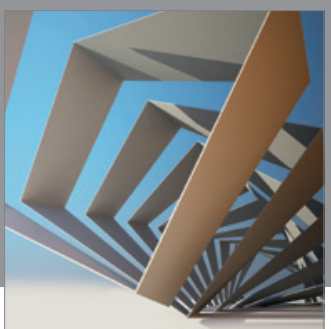

Rotating

Machinery
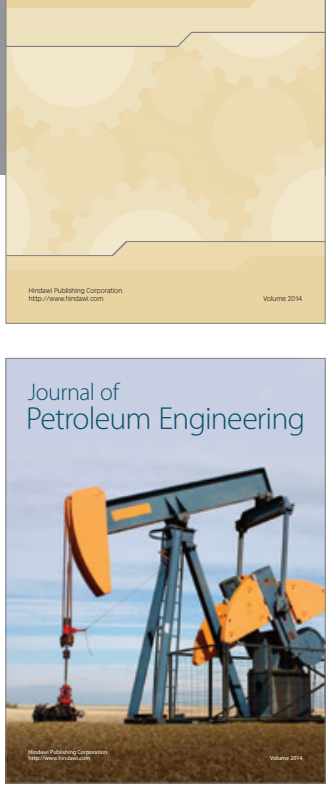

Journal of

Solar Energy
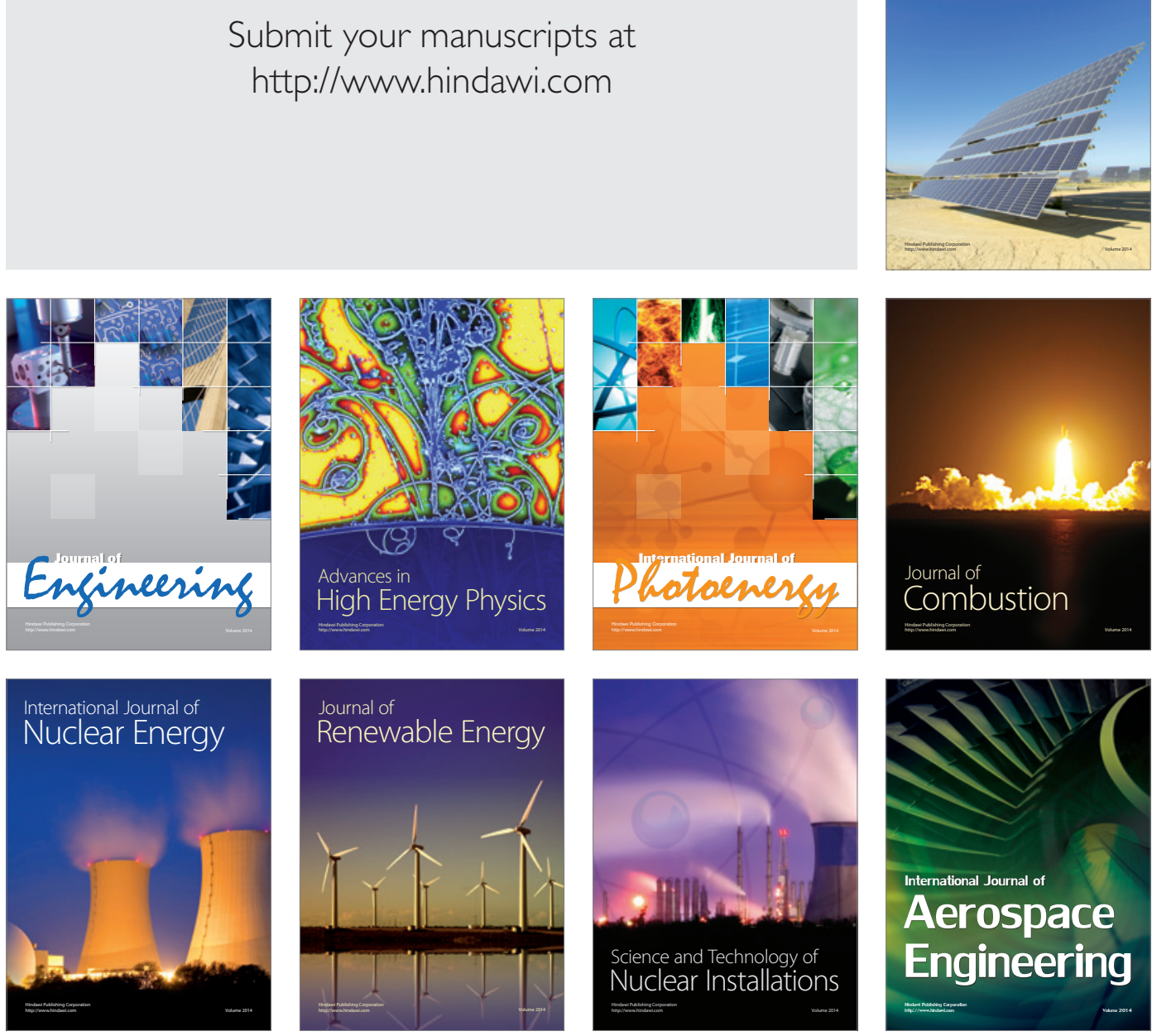